\title{
À CABEÇA CARREGO A IDENTIDADE* O ORÍ COMO UM PROBLEMA DE PLURALIDADE TEOLÓGICA
}

\author{
João Ferreira Dias ${ }^{* *}$
}

\section{O que fica do que passa}

Não é por acaso que Stephan Palmié começa o seu artigo, "O trabalho cultural da globalização iorubá", ${ }^{1}$ por perguntar se Samuel Johnson era, de facto, yorùbá, na medida em que Johnson não passou, ipso facto, de um Sàró cristianizado que somente em retrospetiva é passível de ser entendido como yorùbá, uma vez que toda a sua vivência foi pautada pela cristianização dos povos falantes da língua de $O y$ yọ e suas derivadas e similares. Como Palmié demonstra, a partir do caso dos Lucumí de Cuba, a pergunta é de extrema importância, na medida em que a "iorubidade" (como ele chama) ou a "yorùbánidade" em termos nossos, é de facto resultante de um processo intenso de laboração intelectual e, naturalmente, de um processo de alteridade ${ }^{2}$ que infere na constituição do "eu" yorùbá, quer face aos seus vizinhos africanos, quer face aos missionários cristãos, islâmicos do norte e povos de destino da trata de escravos. Enquanto pastor da Church Missionary Society (doravante CMS), Samuel Johnson observou e formulou a identidade yorùbá em função de uma

* Para o constante, o termo identidade surge em relação ao sujeito individualizado e não aos coletivos designados por yorùbá e afro-brasileiro.

** Investigador do Centro de História da Faculdade de Letras da Universidade de Lisboa. Este texto é dedicado a José da Silva Horta, pela orientação. E-mail: joaoferreiradis@outlook.pt

1 Stephan Palmié, "O trabalho cultural da globalização iorubá", Religião e Sociedade, v. 27, n. 1 (2007), pp. 77-113.

2 François Laplantine, Aprender antropologia, São Paulo: Brasiliense, 2000, p. 21. 
utopia cristã. Jamais foi seu intento construir uma identidade africana em torno de padrões religiosos autóctones. Como J. D. Y. Peel ${ }^{3}$ bem denota, a agenda político-cultural-religiosa de Samuel Johnson era fruto, também, da necessidade de um africano cristão se sentir em casa numa terra da qual os seus pais haviam sido levados como escravos. Johnson era um estranho na sua terra ancestral.

Mas Samuel Johnson não é caso singular. Samuel Ajayi Crowther deve ser descrito nos mesmos moldes. O primeiro bispo anglicano africano foi, a par de Johnson, um proto-yorùbá, na verdade um Sàró inscrito no imaginário yorùbá pelo mesmo processo de Johnson (a que Arthur Danto chama de "alinhamento retrospetivo"4). Educado em Inglaterra, Crowther é celebrado como um yorùbá, hoje em dia. Todavia, tal como o seu contemporâneo Johnson, Crowther foi um missionário cristão em terras africanas que, por mero acaso, era também africano. Com Vocabulary of the Yoruba Language de 1843, Crowther dá um impulso significativo à assunção do termo yorùbá como designador de identidade. Todavia, o processo que o termo haveria de tomar nada teria a ver com os propósitos da CMS. A "comunidade imaginada" que Sigismund Köelle ${ }^{6}$ também preconizava, e que, no fundo, era a aspiração da CMS, era dimensionalmente diferente do que esta se tornaria. Uma Roma africana enquanto projeto ideológico estava muito distante da intensa dinâmica das sociedades proto-yorùbá e daomeanas. Em derradeira análise, a CMS teve o condão de dar o mote a um projeto de reconfiguração identitária africanista (num sentido de valorização do "eu" africano). O velho Eyo Country dá lugar ao território yorùbá. Aos poucos, as populações vão assumindo para si essa nova identidade, cuja longa marcha Peel ${ }^{8}$ bem palmilhou, o que torna desnecessário o ato de caminhar sobre as mesmas pegadas.

\footnotetext{
J. D. Y. Peel, Religious Encounter and the Making of the Yoruba, Bloomington: Indiana University Press, 2001.

4 Arthur Danto, Analytical Philosophy of History, Cambridge: Cambridge University Press, 1965.

5 Benedict Anderson, Imagined Communities: Reflections on the Origin and Spread of Nationalism, London: Verso, 1991.

Sigismund Köelle, Polyglotta Africana, London: Church Missionary House, 1854

Samuel Ajayi Crowther apud Peel, Religious Encounter, p. 284.

Peel, Religious Encounter.

12 Afro-Ásia, 49 (2014), 11-39
} 
A meios de todo um intenso processo de autopercepção e autofabricação, foi-se dando uma maturação cultural comumente descrita como lagosian renaissance ${ }^{9}$ que se expressava em contraponto com o avanço do Cristianismo e dos ideais da CMS, ou seja, pela valorização da negritude e dos seus aspetos mais expressivos: os trajes, a gastronomia, a língua e, necessariamente, a religião. É precisamente quando o Império de Ờọ era já inexistente - Matory chama-lhe com sentido poético de "O Império que já não é" (tradução do autor) — que a valorização do seu ideal melhor se expressa. A nostalgia por uma "idade de ouro" em boa medida tão utópica quanto o referencial cristão face a Jerusalém, ${ }^{10}$ reflete bem, em todo o caso, a procura por uma identidade alternativa em que a alteridade estava bem patente.

Todavia, o que aqui importa, reconhecendo a construção histórica da identidade yorùbá, é observar que tal se fez acompanhar de um processo análogo em relação à religião. Ou seja, importa ter presente que o que constitui a "religião tradicional yorùbá" é, na verdade, uma "tradição inventada", no verdadeiro sentido hobsbawmiano. ${ }^{11}$ Dessa forma, o presente trabalho pretende dar conta de uma pluralidade discursiva, no constante face ao orí, elemento de vitalidade religiosa em ambos os lados do Atlântico. Tal pluralidade discursiva esbarra em certa tradição quer académica quer presente no discurso das comunidades religiosas yorùbá-descendentes, que é a ideia de que a ẹsìn ibilẹ, ${ }^{12}$ a "religião tradicional" nos termos de Matory, ${ }^{13}$ oferece um

9 J. Lorand Matory, Black Atlantic Religion: Tradition, Transnationalism, and Matriarchy in the Afro-Brazilian Candomblé, Princeton: Princeton University Press, 2005.

10 Visível no hino religioso: "Jerusalém que bonita és/ ruas de ouro, mar de cristal...".

11 Terence Ranger e Eric Hobsbawm (eds.), The Invention of Tradition, Cambridge: Cambridge University Press, 1992

12 Não obstante à existência do termo ișẹdálẹ, que nos foi traduzido por Adekanmi como "fatos aborígenes relativos aos Yorùbá, incluindo tradição, cultura, oralidade, terra e crenças", o Dictionary of Yoruba Language de 1913, da CMS, traduz religião por ìsin, do mesmo modo que Roland Hallgren, The Good Things in Life: a Study of the Traditional Religious Culture of the Yoruba, Lund: University of Lund,1991, ao passo que Matory, Black Atlantic Religion, usa especificamente o termo èsin ibílè, como 'religião tradicional'. No caso do English-Yoruba/Yoruba-English Modern Practical Dictionary, de Kayode J. Fakinlede, o termo religião é traduzido por igbàgbó, esin e isin. Bem assim, reconhecendo que esse termo é limitativo para o ambiente em questão, consideram-se válidas as alternativas como orò ilé șișe ou àșà, que denotam um referencial em matéria de localidade que melhor espelha as dinâmicas locais próprias da religião, que salientámos também no trabalho João Ferreira Dias, "Fórmulas religiosas entre os Yorùbás: Olódùmarè, Òrìsà, Àsẹ, Orí e İpin” (Dissertação de Mestrado, Universidade de Lisboa, 2011).

13 Matory, Black Atlantic Religion. 
discurso coerente e conceptualmente unitário. ${ }^{14}$ Observar-se-á tal facto a partir do complexo problema do orí, cujos contornos poder-se-iam inscrever como neotradicionais. ${ }^{15}$ No seio do imenso diálogo necessário, procurar-se-á dar resposta à questão: “Afinal, para quem é o bọí?". Tal pergunta é, pois, uma alegoria para a já mencionada pluridimensionalidade discursiva própria de uma religiosidade dinâmica e fluida.

\section{A vasilha da identidade e o complexo discurso teológico}

A constituição de um discurso religioso que padroniza e tipifica a religião, arrumando-a como paradigma unitário, tem um sentido ideológico e político mais importante do que a própria unidade em si mesma. Como Berliner e Sarró ${ }^{16}$ fizeram questão de salientar, a religião é um produto cultural que se transmite e aprende/apreende. Ora, nos discursos de constituição de identidade, quer cultural quer religiosa, a transmissão de conteúdos é o veículo de consolidação de tradição (reconhecendo-se o primado de Hobsbawm e Ranger). No caso yorùbá, tem particular interesse tal assunção. A constituição da "religião tradicional" (enquanto projeto político e cultural do renascimento lagosiano) pressupõe a veiculação de um determinado conjunto de princípios religiosos que se constituem como alinhamentos sincrónicos que globalizam determinados localismos em detrimento de outros. Este rearranjo tem naturalmente uma função política: dar coerência e unidade a um contexto cultural só em parte realmente unitário. A duplicidade do processo - constituição de "comunidade imaginada" e "invenção de tradição" - espelha bem o tamanho da engrenagem posta em marcha. A apropriação da figura de Odùduwà com um propósito de unificação identitária faz parte da retórica histórica da "yorùbánidade", diante dos antagonismos culturais e políticos, crian-

\footnotetext{
14 Como menciona Thomas Mákanjúọlá Ilésanmí, "The Traditional Theologians and the Practice of Òrìsà Religion in Yorùbáland”, Journal of Religion in Africa, v. 21, n. 3, (1991), p. 220, somente no Sistema de Ifá se pode falar em unicidade discursiva em matéria religiosa yorùbá.

15 Sobre a definição de identidade religiosa yorùbá neotradicional, sugere-se a leitura da obra de Rolland Hallgren, The Vital Force: a Study of àșe in the Traditional and Neo-Traditional Culture of the Yoruba People, Lund: University of Lund, 1995 e a amplificação dada em Dias, "Fórmulas religiosas entre os Yorùbás".

16 David Berliner e Ramon Sarró (eds.), Learning Religion: Anthropological Approaches, Oxford: Berghahn, 2007.
}

14 Afro-Ásia, 49 (2014), 11-39 
do uma verdadeira "farsa", para usar os termos de Adésojí. ${ }^{17}$ Todavia, importa notar que essa "farsa" foi, na verdade, um instrumento político e cultural poderoso numa época em que uma sociedade diametralmente oposta parecia querer erguer-se. A Egbé Omọ Odùduwà, fundada, em 1948, por proeminentes figuras da contemporaneidade histórica yorùbá, como Chief Obáfẹ́mi Awólộwọ̀, um dos founding fathers da Nigéria, é exemplo tardio da importância que o discurso unitário teve para a história moderna da região; e o papel jogado pela figura mitológica de Odùduwà, explorada ao máximo com esse propósito unitário, não pode ser negligenciado. Ainda na esfera política mas numa outra dimensão, mais local, vale a pena citar os bardos reais de Òyó, os Arọkin, e o seu papel na valorização nostálgica da identidade do alafinato, assunto notavelmente analisado por Paulo de Moraes Farias. ${ }^{18}$

Mas a constituição unitária yorùbá não é independente da religião, ou melhor, de uma instrumentalização dos costumes religiosos autóctones, agora endereçados como "religião tradicional"; uma valorização de costumes religiosos que haviam sido obscurecidos e desvalorizados por uma longa tradição literária cristã, dos quais se pode citar Baudin ${ }^{19}$ e Borghero, ${ }^{20}$ a título de exemplo, contemporâneos deste processo de elaboração proto-yorùbá. Essa valorização da tradição africana nativa tinha nas velhas divindades importante vetor. Como refere Matory: "Ífá, Odùduà e Șàngó assumem lugar central em qualquer discussão, no século XX, acerca das tradições coletivas, culturais e políticas Yorùbá" (tradução do autor). ${ }^{21}$ Impera reforçar a ideia de que não é por acaso que são essas as divindades citadas. Começando em ordem inversa, Șàngó, divindade do fogo e trovão, representa a linhagem imperial de Òyó, cidade-símbolo do velho paradigma cultural que serviu a Johnson de modelo realinhado. Òduduwà é o símbolo máximo da unidade política

17 Abimbola Omotayo Adésojí, "The Oduduwa Myth and the Farce of Farce of Yoruba Unity", EnterText, v. 6, n. 3 (2006-2007), <http://www.brunel.ac.uk/faculty/arts/EnterText>, acessado em 24 de julho de 2012.

18 Paulo Fernando de Moraes Farias, "Enquanto isso, do outro lado do mar... os Aròkin e a identidade iorubá", Afro-Ásia, n. 17 (1996), pp. 139-55.

19 Noël Baudin, Fétichisme et féticheurs, Lyon: Bureaux des Missions Catholiques, 1884.

20 Francesco Borghero, Le Dahomé, souvenirs de voyage et de mission, Tours: Alfred Mame et Fils, 1872.

21 Matory, Black Atlantic Religion, p. 61. 
e cultural yorùbá, considerado progenitor de todos os reis yorùbá e fundador da cidade-santa de Ilé-Ifẹ. Dessa perspetiva, Odùduwà é a figura mitológica mais exacerbada e instrumentalizada do imaginário yorùbá, não sendo possível dissociar Odùduwà de "yorùbánidade". Por fim, Ifá, divindade e sistema religioso-divinatório sobre o qual se depositará a atenção ao longo do presente trabalho. Não se nega que outras divindades são amplamente importantes, de acordo com experiência direta com a realidade religiosa yorùbá, como sejam Obatálá, Ợ̦un, Ògún e Yèmonjá. A escolha de Matory revela bem o alcance político tomado pelas divindades, verdadeiras bandeiras de uma cultura negra e valorizável. A nostalgia tornou-se um sentimento contrastante com uma modernidade oferecida pelo Cristianismo. Todavia, ao contrário do proposto por Parrinder, ${ }^{22}$ os cultos dos Òrìsà não ficaram confinados a um modelo rural (mesmo que seja aí que mais amplitude tenham) mas, nesta dialética de valorização de africanidade, fruto do já citado renascimento de Lagos, souberam encontrar o seu espaço no tecido urbano, apesar de ser na cidade que o Sistema de Ífá mais opera. No entanto, as cidades não estão despidas de religiosidade autóctone, ao ponto de Jacob Olupọna ${ }^{23}$ falar em "religião civil" em relação à deusa do rio com o mesmo nome, Òșun. Nesse sentido, nem as aspirações da CMS nem as previsões de Parrinder se revelaram reais. Festivais como İwúdé, Árgúngún, Ọ̀șun ou Gẹlẹdẹ têm assistências de milhões de espetadores e centenas de participantes, o que é um sinal de que os padrões religiosos autóctones não desapareceram, permanecendo parte ativa e importante da identidade local e supralocal no espaço da yorùbáland.

Fica, pois, claro que a construção histórica da identidade cultural e religiosa yorùbá se tratou essencialmente de um exercício de laboratório político-ideológico, que preconizava o reconhecimento dos valores e costumes entendidos como "tradicionais" em função do caráter novo que o Cristianismo - particularmente este, na medida em que à época o Islão era assumido como parte da identidade cultural da região, bas-

\footnotetext{
22 E. G. Parrinder, "Islam and West African Indigenous Religion", Numen, v. 6, n.2 (1959), pp.130-41.

23 Jacob Olupọna, "Yoruba Sacred Kingship and Civil Religion in Òșogbo Nigeria", in Joseph M. Murphy e Mei-Mei Sanford (eds.), O’șun Across the Waters: a Yoruba Goddess in Africa and the Americas (Bloomington: Indiana University Press, 2001), pp. 46-57.
}

16 Afro-Ásia, 49 (2014), 11-39 
tando recordar Matory quando cita que o Islão entre os yorùbá era "tão antigo quanto a vida" (tradução do autor) ${ }^{24}$ — apresentava. Se, no nível retórico, de facto, a afirmação de uma identidade unitária parecia clara e inequívoca, a realidade era, contudo, outra. A pluralidade identitária marcada pelos nacionalismos locais tornava o exercício de homogeneização uma realidade parcial. Se Portugal, a título de exemplo, com as suas fronteiras definidas desde 1249, sendo o mais antigo país europeu, mantém vivos os traços regionalistas, jamais um país africano composto de trinta e seis estados, fundado em 1960, poderia suprimir séculos de assimetrias e regionalismos. A "yorùbánidade" é um guarda-chuva teológico e cultural para a pluralidade interna. Nesse sentido, reconhece-se operatividade ao pressuposto de Ilénsamí:

A heterogeneidade, mais do que a homogeneidade, enquanto facto histórico, conduziu os vários grupos linguísticos 'Yorùbá' a observarem-se a si mesmos muito mais como identidades separadas do que como um todo nacional. Se eram historicamente heterogéneos, poderiam ser religiosamente homogéneos? (tradução do autor). ${ }^{25}$

A heterogeneidade é então um dado fundamental da identidade cultural, política e religiosa dos povos descritos como yorùbá. Ignorar tal facto é metodologicamente perigoso e representa uma má avaliação da realidade do objeto de estudo. Essa pluralidade jamais se poderia traduzir numa homogeneidade religiosa. A diversidade discursiva, no fundo uma diversidade conceptual, é, pois, fruto das significações locais que acompanham a noção de transmissão de conhecimento religioso, o qual produz diversas leituras. Essa pluralidade religiosa, que enfoca, então, as dimensões e matizes locais e familiares e que simultaneamente espelha a plasticidade dos elementos religiosos e culturais em causa, está presente no orí e seus paradigmas adjacentes, i.e., a predestinação e a celebração do mesmo. A unidimensionalidade que subjaz a priori na concepção do orí, dilui-se à medida que vai se tomando o objeto nas suas dimensões várias. Se, en passant, esse pode ser considerado assunto

\footnotetext{
${ }^{24}$ J. Lorand Matory, "Rival Empires: Islam and the Religions of Spirit Possession among the ỌyóYorùbá”, American Ethnologist, v. 21, n. 3 (1994), p. 496.

25 Ilésanmí, "The Traditional Theologians, p. 219.
} 
transparente, sem nódoa teológica e sem contornos menos nítidos, vale a pena desmistificar uma verdade axiomática que é, no fundo, falaciosa. Não apenas no interior da identidade autóctone yorùbá mas também, e talvez acima de tudo, na esfera afro-brasileira do Candomblé.

A densidade temática começa com a definição do sujeito na linguagem religiosa yorùbá. Mesmo sabendo que, lato sensu, o sujeito é composto por corpo (àrá), cabeça (orî) e espírito (ẹmî), surgem ainda o coração (okàn), concebido como portador de conhecimento, o que equivale a uma herança europeia expressa em francês por savoir par cour; as pernas (ẹè)), os joelhos (orúkún), os dedos (ika ẹsẹ), a canela (ojúgun), a planta do pé (àtẹlẹsẹ), a boca (ẹnu); enfim, uma pluralidade de designações, quantos são os elementos corporais conhecidos. Isso para já significa que há, na verdade, uma diferença entre a concepção física do sujeito e a concepção metafórica, facto que importa bastante ter presente. Enquanto o avanço científico desdobra as designações físicas e força a língua yorùbá a acompanhar os objetos a definir/designar, o discurso religioso, simbólico e metafórico, mantém as categorias de base: há um corpo, um elemento imaterial que é o componente da vida, e a cabeça, portadora de identidade e vasilha do destino, ${ }^{26}$ o que seria muito cristalino se, no desdobramento filosófico da identidade do sujeito, não tivessem sido acrescentadas as pernas, símbolo do seu empenho e da sua perseverança. ${ }^{27}$ Pode, de facto, tratar-se de uma simples introdução conceptual ao universo simbólico yorùbá, todavia, a introdução de dados novos representa uma nova perspetiva, uma dinamização do fenómeno religioso que por si só constitui uma alteração paradigmática, e que, mais uma vez, espelha a plasticidade religiosa. Introduzir as pernas como elemento de natureza teológica é assumir para o elemento físico uma nova dimensão para além de si mesmo. Dessa forma, o sujeito yorùbá passa a ser constituído de corpo, elemento imaterial, cabeça e, em alguns discursos, de pernas como símbolo individualizado de determinação. Para já não há um discurso hermético e canonizado, mas, antes, a esperada

26 Oladele Abiodun Balogun, "The Concepts of Ori and Human Destiny in Traditional Yoruba Thought: a Soft-Deterministic Interpretation", Nordic Journal of African Studies, v. 16, n. 1 (2007), pp. 116-30.

27 Kólá Abímbólá, Yoruba Culture: a Philosophical Account, Birmingham: Iroko Academic Publishers, 2006.

18 Afro-Ásia, 49 (2014), 11-39 
pluralidade discursiva dinâmica e dialogante. O confronto entre o ideal unitário e a realidade plural ganha novo contributo.

Que a cabeça é a vasilha da personalidade e do destino (ipin) e é composta pelo orí odè (cabeça exterior) e orí inú (cabeça interior ou mística ${ }^{28}$ ), é tema corrente na literatura sobre o assunto. Sabe-se também que há um orí bom (olórí rere) ou mau (olórí burúkú), i.e., que se é portador de um destino favorável ou penoso. ${ }^{29}$ Todavia, o que é já revelador da dificuldade em encontrar uma ortodoxia religiosa yorùbá é a forma como o destino se expressa no sujeito, i.e., se lhe é atribuído ou imposto. ${ }^{30}$ Esse dilema é apenas parte de um intenso problema de natureza filosófico-religiosa, o qual abordámos em trabalho anterior ${ }^{31}$ e que outros autores já endereçaram vastamente. Tema, todavia, menos explorado é a questão da personalidade humana como algo passível de ser exterior ao orí e ao ìpin, pesem embora os trabalhos de Fayemi ${ }^{32}$ e Oluwole,,$^{33}$ dedicados à questão do caráter e da personalidade como agentes per se, argumentos em que o livre-arbítrio atua como fator de sucesso ou insucesso, seguindo a trilha de Abiodun. ${ }^{34}$ Segundo esses, a educação escolar e, acima de tudo, a educação para a cidadania (ou para o que se poderá chamar de "capacitações sociais" enquanto ferramentas de socialização) agem como orientadoras do sucesso e referenciação social do sujeito. Tudo isso ligado ao conceito de İwà Pẹlẹ, desenvolvido por Wándé Abimbólá. ${ }^{35}$ Apesar da variedade citada, a verdade é que as questões da predestinação e da natureza do orí permanecem como centrais no debate da identidade do sujeito entre os yorùbá, ficando esses

28 Balogun, "The Concepts of Ori”, p. 117.

29 Balogun, "The Concepts of Ori", p. 122.

30 Yunusa Kehinde Salami, "Predestinação e a metafísica da identidade: um estudo de caso iorubá", Afro-Ásia, v. 35, (2007), pp. 263-79.

31 Dias, "Fórmulas religiosas entre os Yorùbás".

32 Ademola Kazeem Fayemi, "Human Personality and the Yoruba Worldview: an Ethico-Sociological Interpretation", The Journal of Pan African Studies, v.2, n. 9 (2009), pp. 166-76.

33 Sophie Oluwole, "Who are (we) the Yoruba?" A Key Note Paper Delivered at a Pre-Word Philosophy Day Conference, June 12, at the National Theater, Lagos, 2007 apud Fayemi, "Human Personality and the Yoruba Worldview".

34 Rowland Abiodun, "Identity and the artistic process in the Yoruba aesthetic concept of Iwa", Journal of Cultures and Ideas, v. 1 (1983), pp. 13-30.

35 Wándé Abimbólá, "Iwapele: the Concept of Good Character in Ifa Literary Corpus", in W. Abimbola (ed.), Yoruba Oral Tradition: Poetry in Music. Dance and Drama (Ile-Ife: University of Ife, 1975), pp. 389-420. 
trabalhos como reflexões de natureza filosófica, sobre (no sentido anglo-saxónico de upper) os primados anteriormente referidos. A diversidade conceptual reforça a já largamente mencionada pluridimensionalidade religiosa autóctone que traduz a dinâmica dos localismos.

Não obstante a vasta literatura sobre a questão do destino ou da predestinação yorùbá, que começa essencialmente com Idowu, ${ }^{36}$ há aspetos que merecem uma nova atenção. Como começo de diálogo, importa fazer a súmula de que há uma concepção mais ou menos aberta de que o destino é atribuído ou imposto ao sujeito (o que per se são visões díspares) e que ele deverá cumprir na sua vida terrena; de que o orí é o portador desse destino e é entendido como um Òrìsà individualizado. Em linhas vagas, é isso que a teologia do orí diz. Todavia, da nossa experiência de campo, há um fator que adensa a problemática do destino entre os yorùbá e que tem a ver, em parte, com a tradução linguística. Segundo Adekanmi, entrevistado em 2011, há uma distinção entre destiny (destino) e fate (fado), ou seja, entre ìpin e àyànmọ. ${ }^{37}$ A terminologia inglesa é aqui particularmente importante. De acordo com o Dictionary of yoruba language, publicado em 1918 pela Church Missionary Society (CMS), que constitui edição revista do original publicado por Samuel Ajayi Crowther e que contou com a colaboração do reverendo yorùbá (segundo um já mencionado alinhamento retrospetivo) T. A. J. Ogunbiyi, o termo destiny é traduzido para yorùbá por opin, nkan, tabi e ẹ'nikan, ao passo que ìpin é traduzido por portion (porção). Tal facto é particularmente interessante, uma vez que nenhum dos termos usados para traduzir destino faz parte da linguagem e da literatura corrente sobre o assunto. ${ }^{38}$ Ademais, tal tradução é particularmente significativa, uma vez que nos conduz perfeitamente à ideia de que ìpin é a porção de energia que cabe a cada sujeito e/ou da porção individual do destino coletivo (o que comporta em si já um sentido judaico-cristão de destino universal), ambos podendo caber na definição de orí. Ou seja, a parte de um todo

Bọlaji Idowu, Olódùmarè: God in Yoruba Belief, London: Longmans, 1962.

Adekanmi Adewuyi, natural de Ilésà, Oníșègùn (mestre das plantas medicinais). Entrevista por correio eletrónico Benavente-Lisboa, nos dias 9, 21 e 25 de maio de 2010 e 4 e 5 de agosto de 2011 via Facebook Chat.

38 Fayemi, "Human Personality and the Yoruba Worldview"; Balogun, "The Concepts of Ori"; Salami, "Predestinação", entre outros.

20 Afro-Ásia, 49 (2014), 11-39 
que é o destino coletivo da humanidade. Os conflitos linguísticos face à literatura corrente sobre o assunto não se encerram aqui. Em relação a fate, esse sim surge traduzido, no já mencionado dicionário da CMS, por ipin, opin, idarisi e $i k u$. Parece claro estar-se diante de uma conjugação entre destino e fado, ou, nos termos ingleses, "algo que está talhado a acontecer a uma coisa ou objeto como pré-concebido" e "determinação individual", o que reforça a ideia de porção. ${ }^{39}$ Observe-se agora àyànmọ́ no citado dicionário da CMS, em que é traduzido por fate ou destiny, remetendo in situ para a observação do termo àbáfú. Fado e destino mantêm a cumplicidade. Ora, na observação do termo àbáfú, surge a tradução inglesa de luck (sorte), fortune (fortuna), fate (fado), oferecendo o exemplo de àbáfú mi ni, i.e., "it is my fate" ("é meu fado").

É notório, no presente caso, o claro exercício de alinhamento cultural que as traduções implicam. Traduzir categorias é traduzir concepções do mundo e, nesse sentido, há sempre uma natural perda de matéria ou conteúdo das cosmovisões de partida, a meio de tal exercício. Estabelecem-se pontes, todavia, sobre alicerces frágeis. Tal facto deixa-nos sempre acantonados às possibilidades mais do que às realidades ou, por outras palavras, fica-se sempre limitado às interpretações a partir de um manual de códigos culturais, não raras vezes inoperatórios. Tal assunção é ainda reforçada pelo contexto em que as traduções ocorrem: a CMS. O background cristão e os religious encounters ${ }^{40}$ não podem ser desprezados.

Se já se dispõe de algumas evidências de que uma matriz religiosa yorùbá é tão falaciosa quanto a ideia de um Cristianismo, a nossa interpretação adensa-se com os comentários de Adekanmi, segundo o qual "ìpin é a testemunha do orí, ìpin é a testemunha do nosso fado, aquilo que nos deverá acontecer na vida" (tradução do autor). Ora, até aqui, ìin era a porção do destino coletivo individualizado, o destino pessoal. Segundo Adekanmi, praticante da religião yorùbá e apelidado de "conhecedor da tradição", na linguagem dos seus conterrâneos, o ìpin tem natureza antropomórfica ou pelo menos espiritual por subjetivação.

\footnotetext{
39 Joyce M. Hawkins (comp.), The Oxford Paperback Dictionary, New York: Oxford University Press, 1983

${ }^{40}$ Peel, Religious Encounter.
} 
İpin deixa de ser o destino para ser a testemunha daquele, colando-se a Òrúnmilà/Ífá, divindade e sistema de adivinhação, simultaneamente, pese o facto de Ilésanmí ${ }^{41}$ considerar Órúnmilà não como divindade mas, antes, como o criador do sistema de adivinhação conhecido como Ífá (que será observado adiante). Tal postulado é particularmente significativo, atendendo à tradição de divinização do sistema e da sua divindade, com todo um corpus mitológico bem estruturado. A humanização do método divinatório representa toda uma outra historização da identidade religiosa yorùbá e, não menos importante, um sério problema de natureza teológica, questão que requereria uma investigação de fôlego, envolvendo a história (essencialmente oral), a antropologia, a filosofia da religião e a teologia, sem o garante, contudo, de conclusões necessariamente objetivas. Retomando o diálogo com Adekanmi. Perante sua afirmação de que ìpin é a testemunha do destino, facto que, como visto, conduz à ideia de Ọrúnmilà, coube-nos contrainterrogar com um epíteto da divindade (agente criador do método?), "Elerin ìpin?", ao qual Adekanmi deu a resposta:

Eleri significa testemunha, eleri ni ìpin significa que ìpin é uma testemunha; por exemplo, se você estiver numa situação que necessita de uma solução, mas você não a conhece ou não a tem, o orí poderá ajudá-lo ligando-o a uma pessoa, acidentalmente, uma vez que é seu destino, e será essa pessoa que você encontra que providenciará a solução. Essa pessoa que você encontra tornar-se-á na testemunha do seu destino na vida. İpin é fado enquanto destino é àyànmọ (tradução do autor).

Constata-se que o interlocutor observa a ideia de ìpin numa dupla função, ao mesmo tempo em que dá uma amplitude de ação considerável ao orí, fazendo dele um agente religioso de alguma forma externo à nossa vontade. Por um lado, ipin é, então, o agente que testemunha o nosso destino podendo tomar parte ativa nele ou não, ao mesmo tempo em que o ato de testemunhar está também ligado à divindade Ớrúnmilà; de outro modo, ìpin é o nosso fado, ficando destino definido por àyànmó, com todas as particularidades de acontecimentos exógenos mas que encaminham o sujeito num determinado sentido. Porém, como visto a partir do dicionário produzido pela CMS, os termos não se separam claramente.

${ }^{41}$ Ilésanmí, "The Traditional Theologians", p. 220. 
Nas ligações entre orí e ìpin, i.e., na forma como o "bom" e o "mau" orí condicionam o decurso de vida do sujeito, o nosso interlocutor afirma, perante a questão "Mas nós podemos mudar nosso destino ou ele já está predeterminado?", que,

[...] a sorte percorre diferentes caminhos para assistir nossas orações. Por exemplo, duas pessoas do mesmo sexo, idade, educação, poderão não alcançar o mesmo sucesso por causa do seu orí, o seu fado encarregar-se-á das suas chances e oportunidades. $O$ destino não pode ser alterado, mas pessoas mal-intencionadas poderão atrasá-lo, por essa razão devemos potenciar o nosso destino por meio de sacrifícios, orações e meditação (tradução do autor).

A sorte ou a fortuna entram, então, no diálogo sobre o destino. $\mathrm{O}$ que equivale a uma abertura relativamente à possibilidade de alterar ou não o destino, facto que varia de sacerdote para sacerdote e de autor para autor. Nesse sentido, tal constatação não é de somenos importância. Compreendendo que o debate se inscreve no coração da teologização do pensamento yorùbá ou, por outras palavras, a constituição de um complexo de "padrões de pensamento religioso", ${ }^{42}$ importa ter presente que alternativas teológicas correspondem a diferentes concepções de mundividências, o que equivale a dizer que não há uma unidade dogmática/doutrinal.

O problema adensa-se ainda mais ao observar-se, por exemplo, a obra do bàbáláàwó (sacerdote de Ífá) norte-americano Philip Neimark, The Way of the Orisa. Reconhecendo, contudo, que sua explicação sobre o problema resulta de um processo de reflexão teológica, há nele interessantes postulados para a observação do problema. De acordo com o

\footnotetext{
42 Sobre o problema da teologia em contexto africano e da constituição de uma alternativa conceptual em "padrões de pensamento religioso", ver Dias, "Fórmulas religiosas entre os Yorùbás". Pese a assunção de longue durée de que "teologia" em África diz respeito ao pensamento cristão, ou melhor, ao encontro entre o Cristianismo e as designadas "religiões tradicionais africanas" (Idowu, Olódùmarè; Kwame Bediako, Theology and Identity: The Impact of Culture upon Christian Thought in the Second Century and in Modern Africa, Oxford: Oxford Centre for Mission Studies, 1999, entre outros), alternativas conceptuais assumindo uma ideia teológica africana (própria, ou que de algum modo assume uma especificidade africana, surgem passim, como se verifica em Jacob Olupona e Sulayman Nyang (orgs.), Religious Plurality in Africa: Essays in Honour of John S. Mbiti (Berlim: Walter de Gruyter, 1993); pese embora a tendência à cristianização dos pressupostos metodológicos de teologia africana.
} 
sacerdote e autor, o destino do sujeito pode ser dividido em três partes complementares: àkúnleyan (que Salami diz ser aquilo que é escolhido de joelhos), como sejam os pedidos feitos pelo sujeito na casa de Ajjàlá (divindade oleira que fabrica os orís), i.e., o número de anos de vida, número de filhos, tipos de relacionamentos, etc.; àkúnlègbà, que será o ambiente fornecido para o cumprimento do destino, como o caso de alguém que deseja morrer de doença seja-lhe concedido nascer num período de epidemia geral; em contrapartida àyànmọ é aquilo que não é possível ser alterado. ${ }^{43}$ Também Neimark nos remete, com àyànmoói, para algo inalterável, ao passo que os outros dois elementos, segundo o autor, são mais permeáveis à mudança por ação do sujeito.

Não restam, portanto, dúvidas quanto à complexidade do problema. Outros autores já o fizeram notar. Todavia, se ao problema forem subtraídos quaisquer usos políticos, parece-nos por demais evidente que há uma problematização filosófica e teológica que não permite falar-se em apenas uma visão, teoria ou doutrina. Ademais, importa ter presente que boa parte das questões de natureza filosófica e teológica relativa à religião yorùbá têm no Sistema de Ífá a sua morada. Como se sabe, o Sistema de Ífá é herdeiro da geomancia dos povos islamizados do norte, como os haúça. O problema histórico da interpenetração do Islão africano e da religiosidade yorùbá é antigo, e Parrinder ${ }^{44}$ e Matory ${ }^{45}$ já fizeram uso do assunto. Ora, o problema que se prende com o unitarismo religioso yorùbá é a tendência metodológica (no mínimo perigosa, no máximo sectária) de observar os postulados do Sistema de Ífá como absolutos para a experiência religiosa yorùbá. Esse é um erro grave que os estudiosos da religião yorùbá, por vezes, tendem a fazer prevalecer. Fazemos nossas as palavras de Ilésanmí:

Se a teoria de Ífá se consubstancia nas práticas atuais por toda a Iorubalândia, então justificar-se-ia afirmar que [o Sistema de] Ífá serviu como modelador de toda a vida sociorreligiosa dos Yorùbá, ab initio. Mas não foi o caso (tradução do autor). ${ }^{46}$

\footnotetext{
43 Philip Neimark, The Way of the Orisa. Empowering Your Life through the Ancient African Religion of Ifa, San Francisco: Harper Collins, 1993, p. 150.

44 Parrinder, "Islam".

45 Matory, "Rival Empires".

46 Ilésanmí, "The Traditional Theologians", p. 220.

24 Afro-Ásia, 49 (2014), 11-39
} 
Fica o lamento por Ilésanmí não ter levado a sua inflexão até aos limites da religiosidade yorùbá. Contudo, o problema está expressamente enunciado. O Sistema de Ífá é, tão somente, um dos vários segmentos religiosos do espaço conhecido por yorùbáland. Não exclui nem encerra em si a identidade religiosa yorùbá, ainda que tal ideia se tenha perpetuado e promovido, nomeadamente pela amplitude dos trabalhos de Wándé Ábímbọ́lá, entre outros. Toda a formulação teórica em torno das divindades em contextos locais, ligados ao sacerdócio das divindades, representa formas alternativas de constituição de saber religioso e de tradição popular, que fica fora das fronteiras de Ífá, um sistema religioso mais hermético e que opera com categorias de tradição judaicodescendente, nomeadamente a ideia de ser supremo, expresso ali em Olódùmarè ${ }^{47}$ A ideia de unitarismo religioso yorùbá influenciou trabalhos como o de Juana Elbein dos Santos, ${ }^{48}$ alicerçado, sobremaneira, nos postulados do Sistema de Ífá e num pensamento estruturalista que pouco operatório se mostrou, ao agrupar divindades nomeadamente em "da esquerda" e "da direita", sem expressar à esquerda ou à direita $d o$ $q u e ̂$ tais estão (ficando-se imediatamente com a sugestão do imaginário cristão de "à direita do Pai").

\section{Para quem é o bọrí? Diversidade teológica yorùbá e afro-brasileira}

Partindo-se de Juana Elbein dos Santos, entra-se na ponte entre o imaginário yorùbá e o afro-brasileiro, ponte levantada por um saudosismo africanista (uso especialmente quando o termo é associado a "saudosismo") no seio da comunidade candomblecista desde meados dos anos de 1930, altura em que os conceitos de "pureza" e "degeneração" começam a surgir no discurso dos terreiros da Bahia. Continuando a fazer do orí o nosso objeto de estudo, pretendemos observar o problema

\footnotetext{
47 Pierre Verger, "O Deus supremo iorubá: uma revisão das fontes”, Afro-Ásia, n.15 (1992), pp. 18-35; Sandra Greene, "Religion, History and the Supreme Gods of Africa: a Contribution to the Debate", Journal of Religion in Africa, v. 26, n. 2 (1996), pp.122-38; Peel, Religious Encounter; Ilésanmí, "The Traditional Theologians"; entre outros.

48 Juana Elbein dos Santos, Os nagô e a morte: pàde, àsèsè e o culto ègun na Bahia, Petrópolis: Vozes, 2001.
} 
do bọrí, a cerimónia de alimento à cabeça mística, em ambos os lados do Atlântico. Procurando entender para quem é celebrado o borí (que é o mesmo que perguntar quem molda/fabrica os orís) inferir-se-á a sua dimensão teológica, sempre sob a necessária ressalva de que não se buscam essencialismos religiosos - que tendem a correr em direção à unidimensionalidade discursiva - , mas, antes, se reconhecem os plurais entendimentos, resultantes necessariamente do aprendizado religioso, nos termos já mencionados de Berliner e Sarró.

Apesar de não alinhar com a afirmação de Palmié ${ }^{49}$ de que Idowu é um teólogo yorùbá, considerando-o, antes, como um teólogo cristão-metodista em contexto cultural yorùbá, o que será amplamente diferente, importa observar o que o pastor e autor registou sobre a questão do destino e do orí. Preocupado com questões de natureza cristã em contexto africano, Idowu observou o orí como a alma do sujeito, amplamente ligada a Olódùmarè:

É premente reenfatizar a ligação entre orí, a essência do ser e Òrìșè, a "cabeça-origem" do sujeito. Òrìsè é Olódùmarè Ele mesmo, como já notámos. O orí que é a essência da personalidade, a personalidade-alma do Homem, deriva diretamente de Olódùmarè cuja única prerrogativa é colocá-lo (orí) no Homem, porque Ele é a inesgotável força da vida. Isso significa que sem Ele não há existência (tradução do autor). ${ }^{50}$

Em Idowu, não restam quaisquer dúvidas de que o orí começa e termina no ser supremo Olódùmarè, apropriado do Sistema de Ífá. Contudo, Idowu não exclui da sua análise os sacrifícios ao orí, mesclando discurso evangélico com análise etnográfica. Curioso facto é que adiante Idowu irá falar no orí como o "anjo da guarda" do indivíduo e conteúdo do destino, razão pela qual ele deve ser alimentado. Tem-se, mais uma vez, uma coabitação entre princípios religiosos distintos, a partir de um processo de uniformização narrativa, na verdade plástica, que não apaga a pluralidade discursiva. Em suma, em Idowu, o orí é fabricado por Olódùmarè e é simultaneamente o contentor do destino e da personalidade e o "anjo da guarda" do sujeito, sendo que os sacrifícios

9 Palmié, "O trabalho cultural", p. 96.

50 Idowu, Olódùmarè, pp. 170-1.

26 Afro-Ásia, 49 (2014), 11-39 
envolvem obi (kola), peixe, e, por vezes, animais sacrificados, pelo que o obi é colocado na fronte por onde o sangue será derramado. Balogun ${ }^{51}$ refere que os orís são moldados por Olódùmarè, embora reconheça uma tradição alternativa que fixa Ȧjàlá como o oleiro, pese o facto de lhe atribuir personalidade menos positiva. Aduplicidade doutrinal reflete a pluralidade de interpretações, que se adensam quando observa-se que Ȧjàlá é, umas vezes, visto como divindade, outras, como epíteto de Òoṣàálá, como é visível no cântico louvativo a essa divindade, utilizado algumas vezes no Candomblé durante a cerimónia do bọrí, ou que "vira" (provoca o transe) os àbiọns (sujeitos em vias de iniciação; literalmente "a caminho de nascer") durante cerimónias como o xirê (celebrações públicas):

Àjàlá mo orí mo orí mo yo àlà forí kọn

E àgò fi rími.

Àjàlá fez a minha cabeça a minha cabeça

Me germinou e fez crescer, àlà que segura e mantém

A minha cabeça. ${ }^{52}$

Entra-se, assim, na questão de quem, afinal, fabrica os orís e, dessa forma, para quem é celebrado o borí. Como visto com Idowu, o borí é celebrado per se, i.e., o borí alimenta a cabeça mística do sujeito potenciando o seu destino, destino esse que foi traçado por Olódùmarè. Alternativamente, tem-se Ajàlá como oleiro dos orís mas ligado a Olódùmarè como quem influi o elemento da vida, ou Òoṣàálá entidade agindo como arquidivindade, nas palavras de Idowu, ou autonomamente, se levar-se em conta a tradição sacerdotal de Òoṣàálá.

Fica claro que, na tradição yorùbá, diferentes percepções se apresentam sobre a mesma categoria religiosa, oferecendo matizes a um pensamento que a priori tenderia a ser tomado como unívoco. Perante

1 Balogun, "The Concepts of Ori".

52 Altair B. Oliveira, Cantando para os Orixás, Rio de Janeiro: Pallas, 2007, p. 152. A tradução do verso sagrado é de Altair B. Oliveira, pelo que é-nos inimputável responsabilidade por quaisquer erros de tradução. Em todo o caso, Adekanmi diz-nos que "esta é uma canção sobre um bom trabalho realizado por Ajalá quando ele fez uma nova cabeça espiritual, e a paz surgiu na vida em questão, e tal facto causou alegria (yo, contração de ayo)". (tradução do autor) (Facebook, 24 de junho de 2013). Embora o comentário de Adekanmi se afaste da tradução, o essencial se mantém: a fabricação dos oris por Àjàlá. 
tal facto, o correto será pensar-se em termos plurais, ou seja, em tradições e não em uma tradição monolítica. Segundo Bàbá Adigun Olocun, ${ }^{53}$ “Orí é destino, o seu diretor, aquele que comanda a sua vida" (tradução do autor). A independência em termos de ação religiosa, por parte do orí, aqui expressa é similar à apresentada por Idowu, mencionada anteriormente, embora com o nosso interlocutor o orí surja independentemente de Olódùmarè, como uma realidade religiosa per se. No que concerne ao borí, o sacerdote nigeriano é peremptório e inequívoco: "Borí é oferecer sacrifício ao ori" (tradução do autor), mas adiantando que Ibori é para o ori não para Obatala" (tradução do autor), perante a questão de ligação do orí a Òoṣàálá, levando em consideração tradições já mencionadas também.

As declarações de Bàbá Adigun Olocun reforçam a ideia de que, no imaginário religioso descrito como yorùbá, a tendência de uniformização tem uma amplitude política, tratando-se de uma apresentação uniformizada resultante da afirmação do "eu" yorùbá.

No interior do Candomblé, religião brasileira de matriz africana (mas não só ${ }^{54}$ ) que resulta das reconfigurações e interpenetrações culturais africanas no Brasil,$^{55}$ a pluralidade interpretativa está também patente, não estando independente da própria dinâmica de "reafricanização" do Candomblé. ${ }^{56}$ Antes de mais, observem-se as palavras da Iyálóòrì̦ăa ${ }^{57}$ Sussu, matriz kétu da Casa Branca do Engenho Velho, que nos disse:

O borí é um ritual muito importante, é um começo no Candomblé, representando uma ligação entre o "filho de santo" e o seu Òrị̀à, entre o "filho de santo" e Òoṣàálá que é quem faz as cabeças. O "eborizado" passa a ter um vínculo com o Òrị̦̀à, mas não tão forte como a iniciação, pois essa tem o èjẹe a navalha à cabeça. O borí é algo que deve acontecer algumas vezes ao longo da vida, porque a cabeça precisa ir comendo para que a vida do

\footnotetext{
53 Príncipe yorùbá, natural de Òșogbo a viver na Alemanha, de onde dirige a Ibile Faith Society, tendo iniciado inúmeras pessoas em diferentes lugares do mundo, no que chama de "religião tradicional Yorùbá”. Entrevistado via Facebook, a 18 de setembro de 2012.

54 Vide Matory, Black Atlantic Religion.

55 A título de exemplo, vide Luis Nicolau Parés, A formação do Candomblé: história e ritual da nação jeje na Bahia, Campinas: Editora da Unicamp, 2006.

56 Sobre os processos contemporâneos, vide Stefania Capone, A busca da África no candomblé: tradição e poder no Brasil, Rio de Janeiro: Pallas, 2005.

57 Título yorùbá para sacerdotisa, traduzido em linguagem corrente por "mãe de santo".
}

28 Afro-Ásia, 49 (2014), 11-39 
"filho de santo" vá correndo bem, para que ele esteja em paz e harmonia com os Òrịsà, em particular com Òoṣàálá, que é quem faz as cabeças. ${ }^{58}$

Sua resposta é particularmente interessante porque reforça a ideia de destino já conhecida, mas traz a ideia de que os orís são moldados por Òoșàálá e, assim, de que o bọí é uma cerimónia para essa divindade, vulgarmente conhecida por Bàbá, 'pai', tomada como pai místico de todos os Òrịsàs e elementos existentes no àiyé, a terra-mundo. Ao mesmo tempo, coloca o borí como uma etapa dentro da vida religiosa, o que confere um sentido diferente ao borí em contexto autóctone africano, no qual o borí se expressa per se..$^{59} \mathrm{Em}$ contexto afro-brasileiro, surge antes da iniciação propriamente dita, descrita na linguagem corrente do Candomblé como "feitura" ou "fazer a cabeça", embora o borí esteja também nela presente. No nível ritual, o borí foi pormenorizadamente analisado por Arno Vogel e colaboradores, ${ }^{60} \mathrm{em}$ contexto kétu ${ }^{61}$ não sendo necessária sua descrição. Importa ainda ver, nas declarações da interlocutora, a componente partilhada no borí entre Òoṣàálá e o Òrìsà do sujeito. Nesse sentido, pode-se considerar que o borí no Candomblé apresenta uma quádrupla inscrição de natureza religiosa: 1) inscreve o sujeito na esfera religiosa, i.e., atribui-lhe identidade religiosa e mística, tornando-o parte da comunidade religiosa, vulgarmente descrita como "família de santo"; 2) alimenta a cabeça mística (orí inú), símbolo de identidade e destino, expressa na afirmação jubilante a ni sòkè, orí bò àiyé, ${ }^{62}$ registada na obra precedentemente ci-

58 İyálóòrìșà Sussu, presidente da Comunidade Portuguesa do Candomblé Yorùbá. Entrevista em Benavente, meados de julho de 2012.

59 Oyeronke Olajubu, Women in the Yoruba Religious Sphere, Albany: State University of New York Press, 2003, p. 33.

${ }_{60}$ Arno Vogel et al., A galinha d'angola: iniciação e identidade na cultura afro-brasileira, Rio de Janeiro: Pallas, 2001

61 "nação" (vide Luís Nicolau Parés, A formação do Candomblé; Vivaldo da Costa Lima, "O conceito de 'nação' nos candomblés da Bahia”, Afro-Ásia, n. 12 (1976), pp. 65-90) de Candomblé considerada a que comporta maior originalidade africana. O que não é necessariamente, a nosso ver, verdade. O terreiro usado como objeto na obra, hoje intitulado Axé Miguel Couto, faz parte da raiz da Casa Branca do Engenho Velho, templo mais tradicional do Candomblé brasileiro. Anteriormente chamado Nossa Senhora das Candeias, o Axé Miguel Couto foi fundado pela falecida sacerdotisa İyá Nitinha, incontornável figura do Candomblé baiano e carioca da segunda metade do século XX e início do XXI.

62 "nós nos regojizamos, a cabeça entrou no mundo" - tradução de Vogel et al., A galinha d'angola, p. 44, Adekanmi, diz-nos que "a ni sòkè" é uma forma de saudação entre sacerdotes durante rituais mas também uma fórmula de encantamento: "we asking did it cry", ao passo que orí bo àiyé, tende 
tada; 3) liga o sujeito a Òoṣàálá, divindade que molda os orís; 4) liga o sujeito ao seu Òrị̀à.

Mas a pluralidade interpretativa não fica por aqui. Ao ser questionado sobre o que é o borí, o Ògán Alágbé $e^{63}$ Vinicius de Santana, filho carnal do falecido Bàbálóòrìsà José Carlos Ibùalámo, natural da Bahia, e grande símbolo do Candomblé paulista, respondeu:

Borí é o ritual específico para alimentar o orí, que é a Divindade que rege a cabeça das pessoas. Na Sociedade Ilé Alákétu Asè Ibùalámo, o Borí é realizado com algumas finalidades, sendo que, para cada uma dessas finalidades, os elementos necessários que compõem o Bọrí podem variar. Há Borí que tem por finalidade acalmar a cabeça de uma pessoa ou, por exemplo, o Borí que é realizado em pessoas já iniciadas, antes de essas realizarem oferendas para os seus Òrìsà. Sobre o último caso, o Borí sempre é realizado antes da oferenda para o Òrìsà, pois acreditamos que, para o Òrìsà receber uma oferenda, é necessário que antes o orí tenha sido alimentado. Essa premissa ocorre também quando da iniciação, que, antes de o Òrìsà ser sacralizado na cabeça de uma pessoa por meio do $O s u$, ela terá passado por um Bọrí, para que sua cabeça esteja apta para receber a energia do Òrisà.

O Bọrí é de fundamental importância no Candomblé, sendo que ele alimenta a Divindade responsável por nossas escolhas, pelos caminhos que vamos seguir, etc. ${ }^{64}$

O depoimento reforça a questão da pluralidade conceptual que pretende-se mostrar neste trabalho. Tal desdobramento conceptual está bem presente quando o ilustre "tocador" de atabaque paulista nos fala da diversidade de fins que compõem a cerimónia do bọrí, o que, para além da tradicional questão de "alimentar" a cabeça mí(s)tica do sujeito, nos oferece uma vasta utilização simbólica do ritual, além da mais ou menos conhecida concepção do orí como canal entre o sujeito e o Òrìsà.

a ser o centro/cabeça onde se fazem os sacrifícios para o mundo. A verdade é que há uma distância entre a tradução do nosso informante e a feita na obra citada, embora o propósito de celebração permaneça.

${ }_{63}$ Ògán, em yorùbá significa 'mestre' e, no Candomblé, é posto masculino que não entra em transe, mas está consagrado a um Òị̀à, sendo uma espécie de ministro ou representante dele. Alágbé é o Ògán que toca atabaque.

${ }^{64}$ Entrevista via e-mail em 24 de setembro de 2012.

30 Afro-Ásia, 49 (2014), 11-39 
Por si só tem-se já uma pluralidade experiencial e construtiva da identidade religiosa no orí, dentro dos candomblés de matriz "yorùbánizante", chamemo-lhes assim, o que equivale a uma ligação à matriz africana autóctone, sabendo que a ponte entre a atual Nigéria e o Brasil influenciou ambos os lados, levando à construção de uma identidade religiosa partilhada. As andanças ligadas ao renascimento lagosiano e à fabricação africanista do Candomblé ocorriam em trânsito atlântico, ao mesmo tempo em que a vasta literatura africana era assimilada e adaptada em contexto brasileiro, a produção literária afro-brasileira era integrada às significações e ressignificações africanas, como nota Hallgren. ${ }^{65}$ Todavia, sabe-se, quer pela análise histórica, quer pela tradição oral, que o Candomblé de matriz kétu se baseia em pressupostos generalistas cujas tradições aportam a Ợọ́ e Ifẹ̀, e simbolicamente a Kétu. Não obstante, a pluralidade étnica proto-yorùbá fez-se sentir no Brasil e está patente nas diferentes "nações" de Candomblé de matriz "yorùbánizante", como Ijexá, Lokiti, Efon, e outras. Tais matizes étnicos proto-yorùbá espelham-se em diferentes processos rituais e padrões de pensamento religioso, ilustrando bem o não unitarismo yorùbá mesmo em contexto de diáspora, onde a ressignificação tenderia a homogeneizar as tradições num processo de invenção e realinhamento imaginário, similar ao cubano abordado por Palmié. ${ }^{66}$

A afirmação de que İyá-orí oferece uma alternativa conceptual a Òoṣàálá como bàbá-orí, i.e., como causa última do borí, ao culto do orí per se, e deste como veiculado a Olódùmarè, colhemo-la junto do Bàbálóòrìșà D. de Oọsọoọsì ${ }^{67}$ Como é sabido, Yèmonjá é uma divindade feminina, das águas, ligada aos ègbá, particularmente a Abẹokúta. ${ }^{68}$ Não é pois de estranhar que Verger tenha registado em İbàdàn cânticos a Yèmonjá chamando-a de ìyá-ori ${ }^{69}{ }^{6} \mathrm{o}$ que é profundamente revelador

65 Hallgren, The Vital Force, p. 62.

66 Palmié, "O trabalho cultural".

67 Pertencente à tradição do Gantois, com casa de Candomblé na região do Porto. Conversa no início de janeiro de 2012.

68 Importante divindade yorùbá, Yèmonjá é símbolo do sagrado feminino, do poder genitor, na grande região de Oỳó e até mesmo em Ifẹ, concorrendo com Ờsun, embora na tradição oral da região de Òyó, Yèmonjá seja celebrada como mãe de Șàngó e esposa de Òòsàálá, cabendo a Òsun o papel de esposa do monarca divino da capital yorùbá.

${ }_{69}$ Pierre Verger, Notas sobre o culto aos Orixás e Voduns, São Paulo: EdUSP, 1999, p. 303. 
de dois princípios importantíssimos a levar em conta: 1) a pluralidade religiosa yorùbá é um dado incontornável que nem o Sistema de Ífá que opera num sentido unificador e hermético consegue suprimir; 2) o primado masculino e o primado feminino se alternam e se mesclam em variados casos. De Ifẹ seguiu para o Daomé o casal Òrișà-Yèmowo (de Òoșàálá-Yèmonjá), que ali se tornou em Mawu-Lisa ${ }^{70}$ o que espelha bem a pluralidade e o caráter transformativo da religiosidade na Costa dos Escravos. O que está em jogo, inegavelmente, é a dialética entre localismos, entre a tradição matriarcal dos ẹgbá e a tradição patriarcal dos ifẹ, a opção entre um primado e outro.

Ainda, as palavras de Opotun Vinicius:

No Ilé Ibùalámo o borí é realizado com o objetivo de alimentar Orí, que é a Divindade que rege a cabeça da pessoa. Essa Divindade é cultuada no Ilé-Orí ou Igba Orí. Além disso, outras Divindades que também possuem forte ligação com a cabeça como um todo são celebradas. Dessa forma, reverenciamos İyá Orí que é tida por nós como a Mãe da Cabeça e Nàná, pois acreditamos que ela é a dona da massa encefálica. Òsàlá é festejado por ser ele o grande responsável pela vida do ser humano, aquele que, por meio do seu sopro divinizado (emi-ofurufi $u^{71}$ ), realiza o milagre da vida, mas não por uma ligação direta com Orí.

É curioso notar, nas declarações do informante, o caráter integrativo das divindades no ritual do borrí. Tal complementaridade que recorda o Sistema de Ífá espelha bem a dinâmica de integração que está na génese do Candomblé. Em suas palavras, o bọí não está dedicado a uma ou outra divindade, mas elas atuam e articulam-se misticamente. Ora, tal reflete que as coisas nem sempre se processam em antagonismos. Como já foi mostrado acima, para a religiosidade yorùbá autóctone, ${ }^{72}$ as coisas

70 Babalola Yai Olabiyi, "From Vodun to Mawu: monotheism and history in the Fon cultural area", in Jean-Pierre Chrétien (org.), L'invention religieuse en Afrique: histoire et religion en Afrique noire (Paris: Karthala, 1993), pp. 241- 65.

71 Independentemente de "emi-ofurufu", aqui referenciado, se tratar de uma utilização/tradução errada do ponto de vista linguístico, para o propósito do presente continuaremos a assumir o primado de aprendizado de conteúdo religioso e a utilidade/significado/valor dentro do quadro comunitário em análise. Assim, no Candomblé e, nesse caso, no Ilé Ibùalámo, Òfurufú (o espaço-atmosfera), é compreendido como o "sopro divino", o hálito criador de Òòsàálá, umbilicado ao èmí, o elemento da vida, o sopro/alma.

72 Dias, "Fórmulas religiosas entre os Yorùbás".

32 Afro-Ásia, 49 (2014), 11-39 
mais se incluem do que excluem. O estruturalismo de feição hermética e antagónica, no qual o àșe se divide rigidamente, e as divindades se agrupam em genitoras, geradas, de esquerda e da direita, que marcou sobremaneira o trabalho de Juana E. dos Santos, ${ }^{73}$ não tem operatividade em contexto africano. As estruturas sociais e religiosas não estão em contraponto, estão em dialética e interpenetração. Como disse J. D. Y. Peel: "todo o sistema se apresenta diferente a partir de diferentes pontos de vista sociais" (tradução do autor). ${ }^{74}$ Nesse sentido, é natural que, em determinadas casas de Candomblé, se processe uma duplicidade referencial, ou seja, que, quer Òòsàálá, quer Yèmonjá assumam um papel de portadores dos orís, o que equivaleria à manutenção do ideal do "casal primordial" já mencionado. A tal facto se junta Nàná, divindade cujo culto em solo africano tem vasta expressão geográfica e simbólica. ${ }^{75}$

Assim, tem-se em evidência uma multiplicidade de interpretações em relação à moldagem dos orís e, dessa forma, ao destinatário da consagração do mesmo por meio do borí. Temos o orí cultuado per se, cultuado em relação a Olódùmarè, em relação a Òoṣàálá, em relação a Yèmonjá e cultuado em relação aos dois anteriores como casal primordial, e compondo uma pluralidade de divindades em conjunto, com Yèmonjá, Òoșàálá e, ainda, Nàná. Isso só por si chega para abalar os alicerces do unitarismo yorùbá, com exceção feita ao Sistema de Ífá que, como escreve Ilésanmí, não é $a b$ initio o forjador da identidade cultural e religiosa na região, mas, antes, um produto histórico posterior. ${ }^{76}$

Merece a pena uma pausa para retomar um primado metodológico em vigência. Embora se reconheça que o termo ișẹșe - que nos foi traduzido por Adekanmi como "primordial; que existe desde o começo dos Yorùbá enquanto povo", e que é sinónimo de ișẹșẹ (termo que no Candomblé é associado aos ritos fúnebres, entendíveis como ritos de passagem e ritos de origem) — aponta para uma lógica pela qual o que

\footnotetext{
73 Santos, Os nagô e a morte.

74 J. D. Y. Peel, Aladura: a Religious Movement among the Yoruba, London: Oxford University Press, 1968, p. 29.

75 Pierre Verger, Orixás, Salvador: Corrupio, 2002, p. 236; Emefie Ikenga-Metuh, "Religious Concepts in West African Cosmogonies: a Problem of Interpretation", Journal of Religion in Africa, v. 13, n. 1 (1982), pp. 11-24.

76 Ilésanmí, "The Traditional Theologians", p. 220.
} 
designa 'religião' em contexto yorùbá seja a valorização e o culto das origens, quer em termos de memória coletiva (que se liga perfeitamente à noção já clássica de inventar tradição) que se expressa macrossistemicamente pela assunção clânica em Òduduwà, quer em termos de linhagem, o que apontaria para o culto dos Ancestrais e, no constante, para a ideia de que o borí, em primeira instância, fosse um rito de consagração do sujeito aos seus progenitores; a verdade é que não podem ser recusadas as afirmações dos informantes como verdades teológicas, porquanto elas revelam os padrões de pensamento apreendidos/aprendidos e aceites dentro da sua linhagem e comunidade religiosa. Por outras palavras, os mitos, os ritos e os padrões de entendimento expressos pelos informantes são, dentro do seu universo referencial e sociorreligioso, aceites como dogmáticos, sendo resultado do aprendizado religioso que tiveram.

Destarte, pese embora o Sistema de Ífá se apresente como um agregador da multiplicidade religiosa do espaço yorùbá, formando um verdadeiro "sistema", a verdade é que não se poderá falar numa unidade sistémica religiosa yorùbá. Odùduwà, Òòsàálá, Yèmonjá e mesmo Olódùmarè e os Ancestrais (Bàbá-Éégún) são articulados de diferentes formas consoante o espaço geográfico tomado e, inclusive, mediante o ponto conceptual de observação. Ou seja, independentemente da formulação própria e padronizada desssa e de outras entidades religiosas (independentemente do seu corpus mitológico), elas são pensadas de determinada maneira em função da organização religiosa em observação e ação - no imaginário de OYyo ', Șàngó, preserva a sua centralidade como culto de Estado, e tanto os Ancestrais como, por exemplo, Yèmonjá, embora mantenham o seu corpus mitológico, estão em correlação específica com aquele, correlação essa que é diferente em relação a Ògún, ou até mesmo a Șàngó noutro ambiente geográfico. O mesmo se aplica quando se muda o ponto central de observação, i.e., quando o culto dos Ancestrais é o ponto de convergência e não, por exemplo, o culto de Șàngó. A transitoriedade dos sistemas revela a impossibilidade de pensar-se em termos de modelo religioso unitário e sistemicamente padronizado e delimitado. O plural impõe-se sobre o singular.

O que fica ainda por discernir, mas que não é tema do presente trabalho, é a natividade yorùbá do borí. Se, por um lado, a sua expressão

34 Afro-Ásia, 49 (2014), 11-39 
ritual parece contar os predicados de prática religiosa africana, i.e., as oferendas, as articulações com entidades religiosas como os Òrìșàs, o propósito de manipulação do extra-humano, a sua formulação parece advir de um outro universo referencial. Não será, pois, de estranhar que o culto yorùbá do orí tenha sido importado dos haúça do norte, ${ }^{77}$ facto que constataria o já mencionado caráter transformativo da religiosidade no espaço da yorùbáland e arredores.

\section{Notas finais}

Grosso modo, a literatura tematicamente africana e afrodescendente em torno da identidade cultural, política e religiosa yorùbá tende a tratar o assunto em função de um unitarismo que facilmente se constata resultar de uma intenção política, alicerçada numa contrarresposta cultural africanista (ou, noutros termos, uma contrarrrresposta em torno de um ideal de ser africano) que procurou valorizar e legitimar a identidade autóctone, diante do avanço islâmico e cristão face aos modelos e sistemas religiosos locais. O trajeto unificador iniciado no seio da Church Missionary Society, em particular por africanos cristianizados como Samuel Johnson e Samuel Ajayi Crowther, tinha por intenção a criação de uma "nação" cristã no seio de um império que já não era mais do que um resquício histórico e uma forte marca da identidade imaginária translocal. O propósito acabaria por servir de mote para um renascimento ideológico africano, fenómeno que finalmente formulou uma identidade designada por yorùbá.

Ora, propósito político à parte, a verdade é que a unicidade yorùbá é mais uma formulação intencional do que real. Nesse quadro, em que se constrói uma narrativa na qual uma ideia de "religião tradicional" ganha forma, as dissimilitudes esbatem-se, quer no nível discursivo quer no interior da literatura, em que o Sistema de Ífá, pelas suas categorias de base judaico-cristã-islâmica, pela sua capacidade aglutinadora em relação

\footnotetext{
77 Sobre o borí em contexto haúça existe toda uma vasta literatura, da qual se podem citar Fremont E. Besmer, "Initiation into the 'Bori'Cult: a Case Study in Ningi Town", Africa: Journal of the International African Institute, v. 47, n. 1 (1977), pp. 1-13; I. M. Lewis, A. al-Safi e S. Hurreiz (eds.), Women's Medicine: the Zar-Bori Cult in Africa and beyond (Edinburgh: Edinburgh University Press, 1991); Adeline Masquelier, "Lightning, Death and the Avenging Spirits: 'Bori' Values in a Muslim World”, Journal of Religion in Africa, v. 24, n. 1 (1994), pp. 2-51; entre outros.
} 
às diferentes divindades do espaço yorùbá, pela sua lógica discursiva universal, pela sua capacidade de adaptação e apropriação de signos exógenos e, não menos importante, pela sua capacidade de produção de conteúdo teológico, se tornou símbolo de identidade religiosa yorùbá, constituindo-se como uma atualização e uma feição moderna dos velhos costumes proto-yorùbá.

Posto isso, levou-se em linha de conta a multidimensionalidade dos conteúdos religiosos yorùbá, que espelham as dinâmicas locais e supralocais de ordenação do extra-humano, facto que dissolve a ideia de unicidade conceptual, ao mesmo tempo em que se reconhece que os processos de transmissão e aprendizado da religião, por parte dos agentes religiosos, reproduzem variadas leituras para o mesmo fenómeno.

No presente trabalho, o objeto de estudo foi o orí, a cabeça na cosmogonia yorùbá, e toda a sua concepção e formulação de natureza teológica ligada ao destino e à personalidade. Pese toda uma tradição ligada à formulação antropológica yorùbá do sujeito, à focalização no orí como vasilha da identidade e do destino, e a uma problemática ligada ao cumprimento e à prescrição fechada ou não de um destino selado, atribuído ou escolhido, que tem por base o Sistema de Ífá, a verdade é que se mostrou que essa é apenas uma tradição, sendo facto que outras interpretações coabitam e convivem. Da análise do dicionário da Church Missionary Society (que, como visto, é produto de um contexto histórico em que se formula a ideia de identidade yorùbá ao mesmo tempo em que se padroniza a linguagem e se traduz a Bíblia) e em função das declarações do informante Adekanmi (yorùbá nativo, herbalista e tradicionalista religioso), compreendeu-se que existe uma distinção entre destino e fado, ou seja, entre ìpin e àyànmó, não obstante a ideia de ìpin surgir ligada ao conceito de porção, i.e., a uma parte individualizada do todo que é o destino coletivo. Tal facto inclui a vivência individual dentro do todo humano, um sentimento não independente das heranças judaico-descendentes de destino universal. A pluralidade de termos yorùbá para designar a ideia de destino e fado denotam a pluralidade de interpretações e a dificuldade da tradução conceptual. Os encontros religiosos estão, longue durée, na génese das transformações e ressignificações identitárias e religiosas.

36 Afro-Ásia, 49 (2014), 11-39 
Não obstante, o problema adensou-se com a antropomorfização do ìpin, nas declarações de Adekanmi, sendo que ìpin, para além de destino, é também sua testemunha, conferindo ao conceito uma dupla função. Ao mesmo tempo, o nosso informante oferece-nos ainda a ação da fortuna, o que possibilita a abertura, ainda que ténue, às alterações do destino, ou pelo menos, do ato de agir sobre aquele. Ainda, de acordo com a observação da obra de Neimark, o destino pode ser dividido em: àkúnleyan (como sejam os pedidos feitos pelo sujeito na casa de Àjàlá), àkúnlègbà, que será o ambiente fornecido para o cumprimento do destino, e àyànmọ, aquilo que não é possível ser alterado. Toda essa pluralidade interpretativa que resulta de diferentes sensibilidades conceptuais serve para provar que a unicidade religiosa yorùbá é uma realidade ténue, se não mesmo falaciosa. O papel do Sistema de Ífá em todo esse processo é centralíssimo, como Ilésanmí atesta.

A natureza filosófica e teológica do orí expressa-se claramente no seu ritual, o borí. Se, em Idowu, o orí está ligado a Olódùmarè, o ser supremo altamente promovido no interior do Sistema de Ífá e que resulta da apropriação e assimilação de categorias religiosas de base judaico-descendente, sendo o borí celebrado per se (mas em função a Olódùmarè, o que deixa as declarações de Idowu num limbo conceptual), no interior do Candomblé de matriz "yorùbánizante", o bọrí apresenta uma notável variedade conceptual que nos endereça novamente à noção de multidimensionalidade conceptual per se, e enquanto produto do aprendizado religioso. Tal facto se denota pela não menção à celebração das origens, ị̦̀ẹsẹ, sejam elas mítico-clânicas, sejam familiares/de linhagem. Observando as declarações dos informantes, compreende-se que é celebrado não apenas como ligação a um destino de que o orí é objeto simbólico, mas, mais notável ainda, apresenta uma pluralidade utilitária (a dimensão utilitária revela por si mesma a plasticidade do fenómeno religioso) e interpretativa. Para além de inscrever o sujeito na esfera religiosa, i.e., atribuir-lhe identidade religiosa e mística, tornando-o parte da comunidade religiosa, vulgarmente descrita como "família de santo" pela comunidade do Candomblé, o borí: 1) alimenta a cabeça mística (orí inú), símbolo de identidade e destino; 2) liga o sujeito a Òoșàálá, divindade que molda os orís e/ou que influi na vida do sujeito; 3) liga 
o sujeito ao seu Òrị̀à; 4) liga o sujeito a Yèmonjá como ìyá-orí, liga o sujeito a Nàná como dona da massa encefálica. Paralelamente, o borri é realizado com objetivos diversos, entre eles acalmar a cabeça do indivíduo e apresentando-se como etapa primária no ritual de iniciação religiosa.

Fica, pois, expresso que o unitarismo religioso yorùbá advém de uma necessidade retórica de natureza política e que tem no Sistema de Ífá - apenas um dos vários segmentos do espaço religioso da yorùbáland $\mathrm{e}$ que é herdeiro do Islamismo místico haúça - seu principal promotor. Isso significa que, dentro do chamado imaginário religioso yorùbá, coabitam diferentes interpretações e diferentes níveis e segmentos de experienciação religiosa, sendo impossível — como vem sendo erroneamente hábito - falar numa religião yorùbá (a não ser como referencial abrangente) sem se cair no erro metodológico de suprimir todas as diferenças que representam a própria identidade religiosa do espaço observado: dinâmica, com grande vitalidade local e com reordenação múltipla em função do eixo de observação. A análise da concepção e ritualidade em torno do orí nos permitiu alcançar todo um vasto quadro interpretativo e utilitário, fornecendo novos dados a um campo de análise tradicionalmente unívoco e unidimensionalmente formatado. Tal ideia equivale a dizer que com este trabalho, de algum modo, se abre um novo campo de possibilidades de leituras, interpretações, significações e configurações sobre os padrões de pensamento religioso yorùbá e afro-brasileiro, e suas expressões rituais.

Não descorando uma ideia de essencialidade religiosa, que pode advir de determinados segmentos religiosos que prevalecem a sua leitura como unívoca, compreende-se do presente que fatores como o aprendizado dos conteúdos religiosos operam no sentido de fabricar narrativas plurais sobre um determinado elemento religioso. Tal facto equivale a dizer que a pluralidade teológica resulta do exercício hermenêutico que lhe é próprio, ao mesmo tempo em que advém da própria dinâmica de adaptação e ressignificação no seio das comunidades religiosas que dão uso aos ritos e referenciais religiosos. Retomando ideia de Ilésanmí: se os yorùbá são historicamente heterogéneos, como poderiam eles ser religiosamente homogéneos? O mesmo se dirá para o Candomblé, verdadeira manta de retalhos de significados e conteúdos religiosos.

Texto recebido em 22 de janeiro de 2013 e aprovado 22 de julho de 2013

38 Afro-Ásia, 49 (2014), 11-39 


\title{
Resumo
}

O presente artigo pretende observar o sentido do orí, a cabeça, entre os yorùbá da África Ocidental, dando conta do complexo problema de natureza teológica subjacente à pluridimensionalidade discursiva dentro de um quadro cultural descrito como yorùbá, quadro esse que compreende a diáspora afro-brasileira com o Candomblé. Tal pluridimensionalidade - em matéria de predestinação, fabricação e natureza do orí e, bem assim, pela diversidade de entidades religiosas para as quais o borí, o ritual de alimento à cabeça mítica, se realiza - se inscreve na dimensão proposta por Berliner e Sarró de aprendizado e transmissão religiosas.

Palavras-chave: orí - predestinação - yorùbá - Candomblé - complexidade teológica

\begin{abstract}
This article intends to observe the meaning of orí (the head, among the Yorùbá people of West Africa). The orí will be the point of departure of a theological complex problem, which expresses plural discourses in the middle of the so-called Yorùbá framework; in fact, a framework where Afro-Brazilian Candomblé takes an important role. Such pluridimensionality is an "all-in-one" in the matter of orí: predestination, fabrication and nature of orí, and the plurality of religious entities quoted in the borí - the ritual of 'feeding' the mythical head. Thereby, dealing with plural discourses in a same and specific matter means dealing with the idea of learning and transmission of religion, as presented by Berliner and Sarró.
\end{abstract}

Keywords: orí - predestination - Yorùbá people - Candomblé - theological complexity 